\title{
Effect of reinforcement fibers on the collapse potential of clayey sands
}

\author{
Souhila Adjabi ${ }^{1}$, Mohamed Salah Nouaouria ${ }^{1} \&$ Cherif Betehi $^{1}$ \\ ${ }^{1}$ Laboratory of Civil Engineering and Hydraulics, University $8^{\text {th }}$ May 1945 Guelma, Algeria.
}

\begin{abstract}
The collapse of soils under wetting is a major problem in Geotechnical engineering. The erection of structures on these types of soils, located in arid and semi-arid zones, needs careful treatment of these soils. Soil reinforcement techniques have been rapidly increased during these two decades because of their effectiveness in geotechnical engineering. The aim of this experimental work is to investigate the collapsible soil behaviour in order to improve its characteristics. To achieve this goal, Polyethylene fibers, and Sisal fibers were used as Polyethylene fibers content in mass are varied from $0 \%$ (unreinforced samples) to 15\%; and Sisal fibers content from $0.5 \%$ to $1 \%$. The fiber reinforcement is combined with other processing procedures such as compaction and the addition of CPA cement to decrease the collapse potential.
\end{abstract}

Keywords: Collapse potential, Polyethylene fiber, Sisal fiber

\section{Introduction}

Construction of buildings and other civil engineering structures on collapsible soils is highly risky because such soils are susceptible to settle suddenly when are loaded and wetted. It is quite common to find soils that do not fulfill the basic necessities of an engineering project technically, economically or in terms of timing. Economic issues have stimulated interest in the development of alternative materials that fulfill design specifications. The well-established techniques of soil stabilization and soil reinforcement are often used to obtain improved geotechnical materials, either through the addition of cementation agents or through the inclusion of randomly distributed discrete elements such as fibers. Stabilized and reinforced soils are composite materials that result from the combination and optimization of the properties of individual constituent materials.

This paper describes a study of the mechanical behaviour of Kaolinite-sand mixed samples reinforced with randomly distributed polyethylene fibers, and Sisal fibers under oedometer loading conditions. The specific objectives of the present work are to evaluate the effect of fiber insertion on the collapse potential of sand samples mixed with Kaolinite in different proportions such as: 0 $\%, 5 \%, 10 \%, 15 \%, 20 \%, 25 \%$ and $30 \%$ respectively, to determine the optimum content of Kaolinite giving the maximum potential collapse.
In its quest to get healthier drinking water, millions of people are using bottled water. The annual global consumption of bottled water has reached billions of liters. This requires the production of innumerable quantities of bottles which are generally thrown in the nature. This act is harmful to the environment. Only about $20 \%$ of plastic bottles are recycled; $80 \%$ end up in landfills, or in nature. Plastic bottles begin to decompose in nature only after hundreds of years. In order to reduce the quantity of plastic bottles, we undertake this study based on the use of this material to treat the collapsible soil. This is in order to protect the environment and to address this type of soil problems by finding economic solutions.

The objective of this paper is to determine the effect of randomly distributed short polyethylene-fiber, and Sisal fibers, respectively, on the collapse behaviour of a clayey sand material. A series of compression tests were carried out in the Oedometer apparatus, on soil samples made of sand, fibers and Kaolinite. Various lengths of fibers were respectively used, such as: $5 \mathrm{~mm}, 10 \mathrm{~mm}$ and $25 \mathrm{~mm}$.

Soil was reinforced with polyethylene fibers contents of $5 \%$, $10 \%$ and $15 \%$ respectively. For each content three different lengths were used $(5 \mathrm{~mm}, 10 \mathrm{~mm}$ and $25 \mathrm{~mm}$ respectively), and $0.5 \%, 1 \%(5 \mathrm{~mm}, 10 \mathrm{~mm}$ and $25 \mathrm{~mm}$ long) for Sisal fibers.

\section{Literature review}

Since the beginning of 1970 s, several investigators have studied stress-strain characteristics of reinforced soil using triaxial, direct shear, and plane strain tests. From 1977, extensive experimental work has been performed on geotextile-reinforced sand. Incorporating reinforcement inclusions within soil is also an effective and reliable technique in order to improve the 
engineering properties of soil. Many investigators have used various types of fibers under different test conditions.

Maher and Ho (1993) evaluated the effect of randomly distributed fiber reinforcement on the response of cemented sand to load. Test results indicated that fiber reinforcement have significantly increased the compressive and shear strength of cemented sand.

Ayadat and Dahili (1998) improved the properties of a collapsible soil, the bituminous treatment of such soil at a depth of less than $4 \mathrm{~m}$ has been examined, the results indicated that for obtaining non collapsible soil, a minimum water content of $4 \%$, a bitumen content between 10 and $12 \%$ and a high compacting energy (more than 80 blows by layer for a total of two layers in oedometer ring) have been applied.

Consoli et al. (2003a) proposed a field application for soil reinforcement for increasing the bearing capacity of spread foundations when placed on a layer of fiberreinforced cemented sand built over a weak residual soil stratum.

Yetimoglu and Salbas, (2003), investigated the effect of fiber reinforcement content on the shear strength of soil. The results of the tests indicated that the peak shear strength and the initial stiffness of the sand were not affected significantly. However the fiber reinforcement could reduce soil brittleness providing smaller loss of post-peak strength, and increases the residual shear strength angle of the sand.

Hamidi and Hooresfand (2013) used the conventional triaxial compression tests to determine the effect of cement and polypropylene fiber reinforcement on sand, the addition of fibers increased peak and residual shear strength of cement treated soil and changed its brittle behaviour to a more ductile one.

Botero and Ossa (2015) studied the mechanical behaviour of a silty soil that was reinforced with randomly distributed PET fibers. The results indicated that the reinforced specimens presented increase of shear strength that was associated with the increasing quantities of the PET fiber.

Chegenizadeh and Nikraz, (2012) investigated the effect of paper inclusion on the modulus of elasticity of subgrade material; the results indicated that the increase of paper percentage in mass slightly increased the modulus of elasticity.

Al Adili and Azzam (2011) studied the effect of soil reinforced with randomly included papyrus fiber on the strength behaviour. The results of these tests have shown a significant improvement in the failure deviator stress and shear strength parameters of the soil with $10 \%$ of papyrus fiber. This addition also reduced the deformation of the soil under loading.

Chauhan and Mittal (2008) investigated the effect of reinforcement with coir fiber and synthetic fiber in the strength of subgrade soil, they reported that the permanent and resilient strains in all materials decreased with confining pressure but increased with the number of load cycles and deviator stress in reinforced and unreinforced conditions.

In comparison with conventional geosynthetics (strips, geotextiles, geogrids, etc.), there are some advantages in using randomly distributed fibers as reinforcement. Firstly, the discrete fibers are simply added and mixed randomly with soil, in the same way as cement, lime, or other additives. Secondly, randomly distributed fibers limit potential planes of weakness that can develop parallel to oriented reinforcement.

\section{Materials, equipment and experimental program}

\subsection{Materials}

\subsubsection{Sand}

The soil used in this investigation was a Kaolinite and sand with the grain size distribution curves shown in Figure 1.

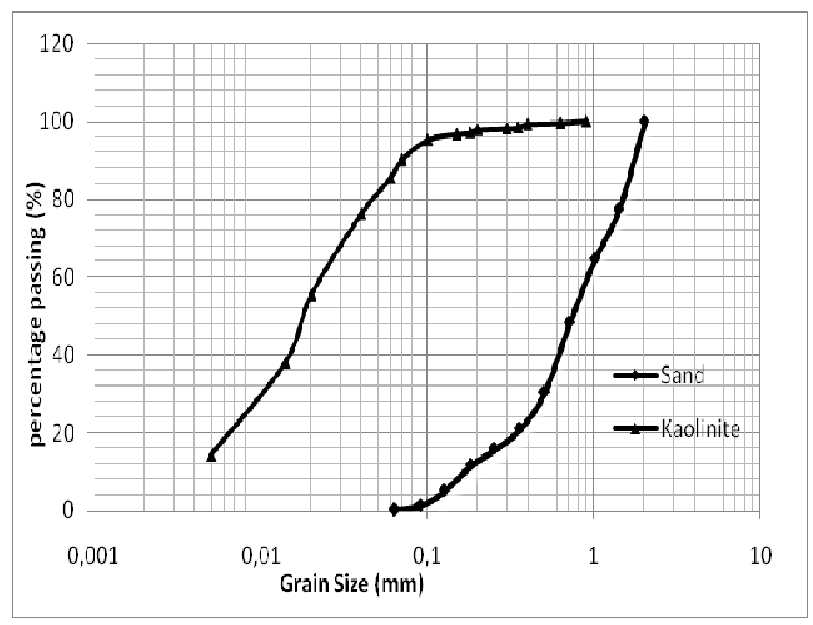

Fig. 1 Particle size distribution curve of sand and Kaolinite

\subsubsection{Polyethylene fiber}

Polyethylene (abbreviated PET) is the most common plastic material. The annual global production is approximately 80 million tones. Its primary use is in packaging (plastic bag, plastic films, geomembranes, containers including bottles, etc.). Many kinds of polyethylene are known, with most having the chemical formula $\left(\mathrm{C}_{2} \mathrm{H}_{4}\right) \mathrm{nH}_{2}$. Thus, PET is usually a mixture of similar organic compounds that differ in terms of the value of $n$.

\subsubsection{Sisal fibers}

Sisal, as shown in Figure 2, is a natural fiber fully biodegradable. It is highly renewable resource of energy. 


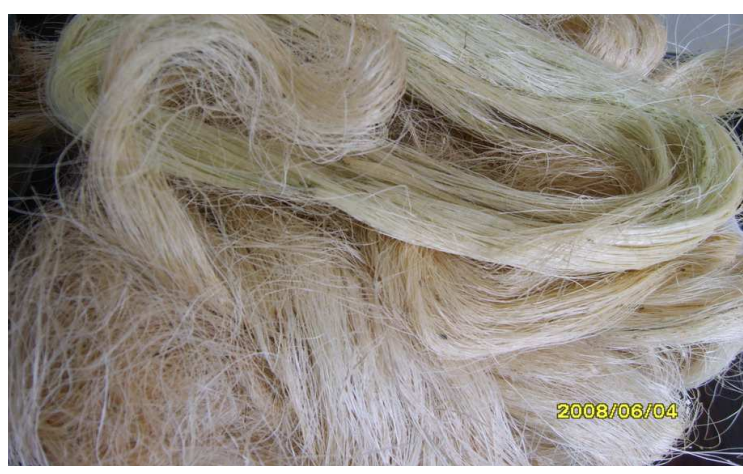

Fig. 2 Sisal fibers

\subsection{Equipment}

\subsubsection{Compacting Device}

The compacting device first designed by Ayadat et al. (1998), is consisted of a vertical stem of $200 \mathrm{~mm}$ long and a diameter of $12.2 \mathrm{~mm}$. It is welded to a horizontal disc of $5 \mathrm{~mm}$ thick and a diameter of $50.2 \mathrm{~mm}$. A discshaped hammer of $136 \mathrm{~g}, 16,4 \mathrm{~mm}$ thick and a diameter of $39.2 \mathrm{~mm}$, with a hole of $12.25 \mathrm{~mm}$.

\subsubsection{Oedometer}

The Oedometer is a laboratory apparatus used in geotechnical engineering. This instrument is generally used to measure the compressibility of a soil sample, preferably intact, under a given applied vertical effective pressure. The operation of loading and unloading is carried out stepwise and is timed in order to determine the compressibility properties of soil.

\subsection{Oedometer test:}

\subsubsection{Sample preparation}

In this investigation, the collapse behaviour is assessed with an initial water of $4 \%$.

The first series of tests were conducted on seven reconstituted samples from sand and Kaolinite in various proportions in mass of Kaolinite/Sand, such as: 0/100, $5 / 95,10 / 90,15 / 85,20 / 80,25 / 75$ and $30 / 70$ as shown in Table 1.

Table 1 Reconstituted samples

\begin{tabular}{|c|r|r|r|r|r|r|r|}
\hline Designation & S1 & S2 & S3 & S4 & S5 & S6 & S7 \\
\hline Kaolinite (\%) & 0 & 5 & 10 & 15 & 20 & 25 & 30 \\
\hline $\begin{array}{c}\text { Normalized Sand } \\
(\%)\end{array}$ & 100 & 95 & 90 & 85 & 80 & 75 & 70 \\
\hline $\begin{array}{c}\text { Water content } \\
(\%)\end{array}$ & 4 & 4 & 4 & 4 & 4 & 4 & 4 \\
\hline
\end{tabular}

The second set of hydrocollapse tests were undertaken on reconstituted samples of sand and Kaolinite. Seven grain size classes of sand are used together with the same content of Kaolinite of $25 \%$ and water content of $4 \%$. The reason of taking $25 \%$ of Kaolinite is that this content has given the maximum collapse potential in the first set of tests. Based on the tests results to investigate the effect of the Kaolinite content on the collapse potential, it was noted that the Kaolinite content $25 \%$ has clearly given maximum collapse potential.

The soil reinforcement was provided by sisal fibers and polyethylene fibers, respectively, in various ratios by mass of fiber/soil, such as: $5 \%, 10 \%$ and $15 \%$. Three different lengths were used: $5 \mathrm{~mm}, 10 \mathrm{~mm}$, and $15 \mathrm{~mm}$. The sand is well mixed with Kaolinite and water content of $4 \%$ in order to obtain homogeneous samples. The sample is then placed into the oedometer ring in two layers.

The hydrocollapse tests were carried out based on the procedure of (Jennings and Knight, 1975).

According to Ayadat et al. (1998), the compaction is made with dropping, hammer from a height of $\mathrm{H}=150$ $\mathrm{mm}$. This hammer slides freely along the vertical rod until it hits the disk that transmits the shock to the sample.

\section{$4 \quad$ Results and discussions}

\subsection{Effect of Kaolinite content on the collapse potential}

The collapse potential is defined by the following expression:

$\mathrm{CP}=\left(\delta \mathrm{h} / \mathrm{H}_{0}\right) * 100$

Where: $\delta \mathrm{h}=\mathrm{H}_{0}-\mathrm{H}_{1}$

$\mathrm{H}_{0}$ is the sample thickness before saturation, and $\mathrm{H}_{1}$ is the sample thickness after saturation. The applied vertical stress at the moment of saturation is taken as the nominal pressure, $\sigma_{i}=200 \mathrm{kPa}$.

Figure 3 presents the effect of the Kaolinite content on the collapse potential. We note that the collapse potential is clearly affected by the Kaolinite content present in the samples. The maximum collapse potential is achieved with an optimum Kaolinite content of about $25 \%$. These findings confirm with the observations made by Lawton and al. (1992), who stated that the maximum collapse is found with clay content between $10 \%$ and $40 \%$ and are in concordance with the results of the investigation

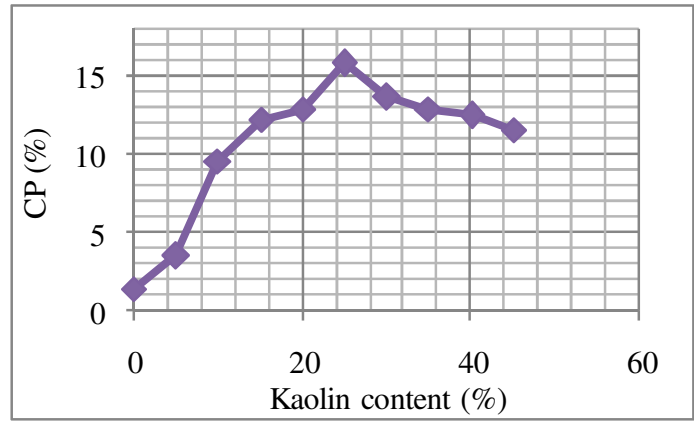

Fig. 3 Effect of the Kaolinite content on the collapse potential 
undertaken Nouaouria and al. (2002), who have shown that the maximum collapse potential was obtained with an optimal percentage of about $25 \%$ of Kaolinite.

\subsection{Effect of sand grain size on $\mathrm{CP}$}

A set of tests were carried out in order to show the effect of the sand grain size on the collapse potential (see figure $4)$. We can clearly see in figure 4 that the potential collapse is approximately ranging between $9.2 \%$ and $13.5 \%$.The maximum value of $\mathrm{CP}$ was found with sand grain size of $500 \mu \mathrm{m}$. According to Jennings and Knight (1975), this type of soil is classified to cause severe damages.

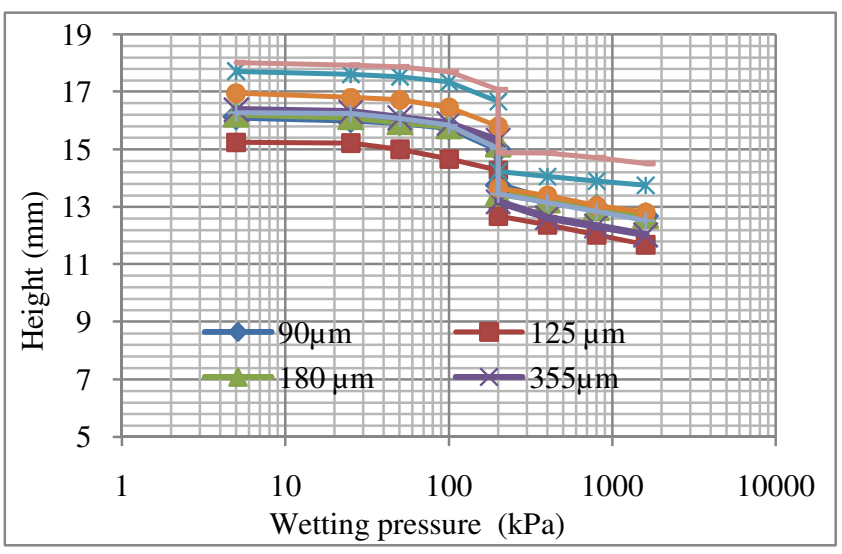

Fig. 4 Hydrocollapse test results

\subsection{Effect of the polyethylene fibers reinforcement}

The specimens used in this series of tests were prepared by mixing $75 \%$ of sand and $25 \%$ Kaolinite. The polyethylene fibers were used in three different proportions, namely: $5 \%, 10 \%$, and $15 \%$ respectively, and in different lengths, as follows: $5 \mathrm{~mm}, 10 \mathrm{~mm}$, and $25 \mathrm{~mm}$ respectively.

The results are reported in Figure 5. It is seen in figure 5(a) that the collapse potential for unreinforced soil is about $17.28 \%$, the addition of $5 \%$ of the polyethylene fibers of $5 \mathrm{~mm}$ long has resulted in a small reduction in collapse potential. Whereas, this collapse potential was reduced to 9.7 with $15 \%$ of polyethylene.

Figure 5-(b) shows the treatment of the soil with polyethylene fibers of $10 \mathrm{~mm}$ long. In this case, there is a small decrease in the value-of collapse potential. Figure 5-(c), with reinforcing fibers of $25 \mathrm{~mm}$ long, decreases from $12.76 \%$ to $10.20 \%$ and then increases with fiber content of $15 \%$. As the collapse is due to the migration of soil particles, during flooding the soil fine particles move through the soil skeleton from one level to another. The increase of polyethylene fiber content beyond $10 \%$ prevents the good compaction and results in an open soil structure which will be subjected to high hydrocollapse.
We can note that the minimum value of $\mathrm{CP}(9.70 \%)$ is achieved with $15 \%$ of fibers of $5 \mathrm{~mm}$ long. Using this type of reinforcement the collapse potential has then decreased by approximately $44 \%$.
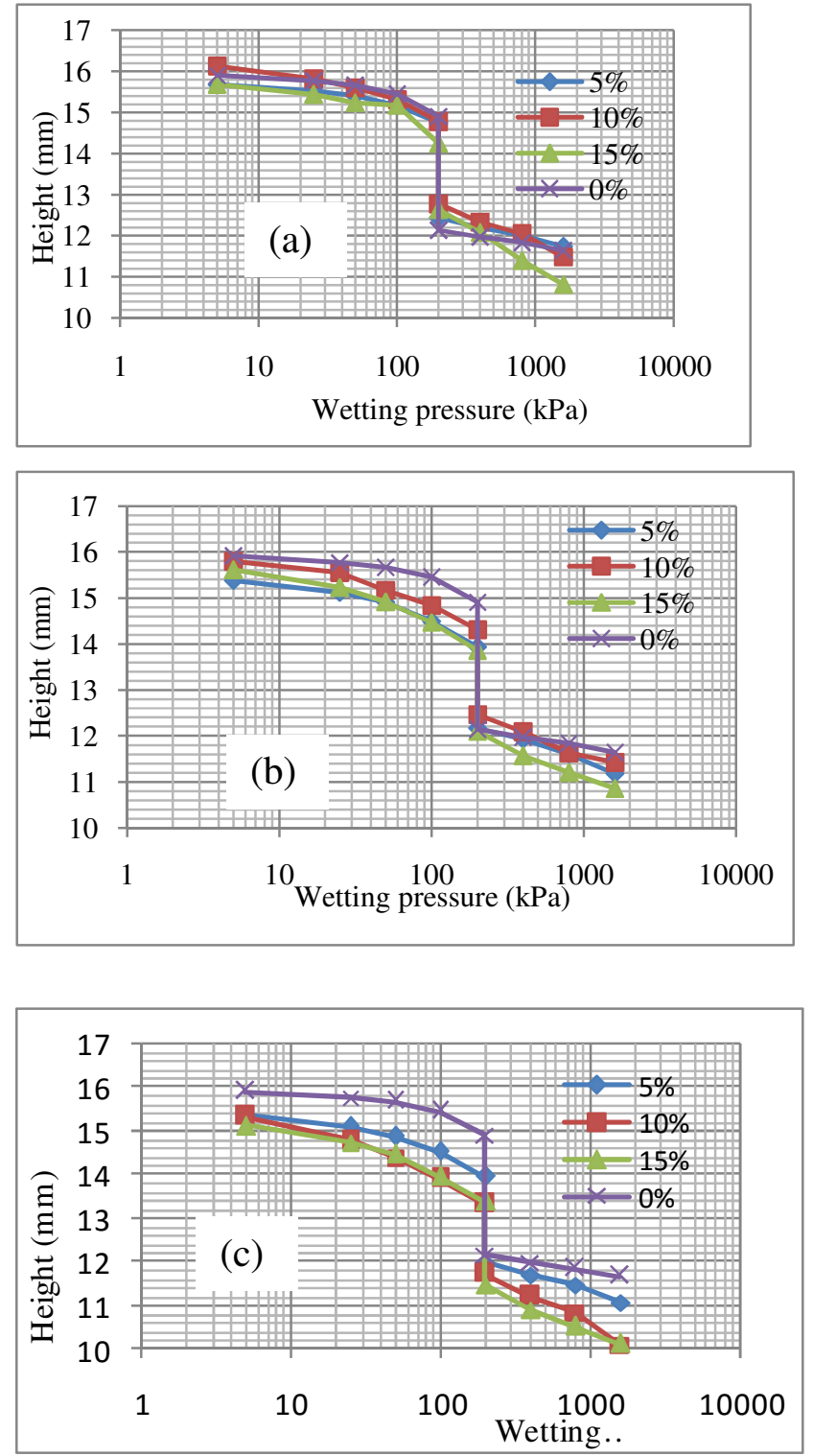

Fig. 5 Effect of Polyethylene fiber on potential collapse a) length $=5 \mathrm{~mm}$, b) length $=10 \mathrm{~mm}$ c) length $=25 \mathrm{~mm}$.

\subsection{Effect of the sisal fibers reinforcement}

The sisal fibers are used in two different proportions, namely: $0,5 \%$, and $1 \%$ respectively, and different lengths, as follows: $5 \mathrm{~mm}, 10 \mathrm{~mm}$, and $25 \mathrm{~mm}$ respectively.

From the results illustrated in Figure 6-(a), it is noted that the collapse potential increases from 12.48 to 15.42 for a $5 \mathrm{~mm}$ long of sisal fiber. According to the figure 6-(b), the collapse potential is ranging from 13.06 to 14.64 for a fiber of $10 \mathrm{~mm}$ long. The only fiber length that decreased the collapse potential was $25 \mathrm{~mm}$ long as clearly shown 
figure 6-(c). The soil treatment with sisal fibers gives a reduction of about $31 \%$.
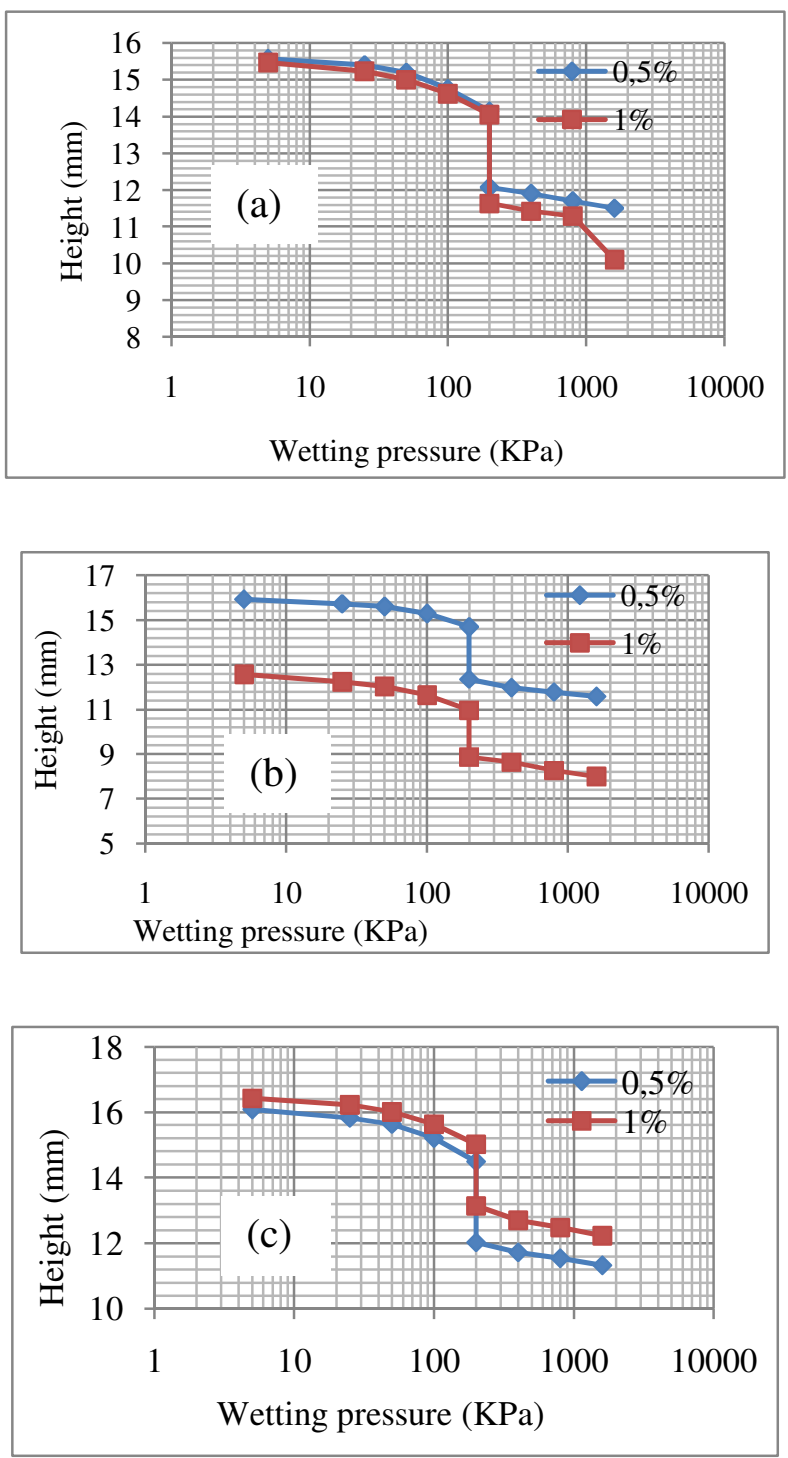

Fig. 6 Collapse potential (a) Sisal fiber length $=5 \mathrm{~mm}$

(b) Sisal fiber length $=10 \mathrm{~mm}$,

(c) Sisal fiber length $=25 \mathrm{~mm}$.

\section{Conclusions}

The objective of this study is to improve the behaviour of a collapsible soil with the inclusion of polyethylene fibers and sisal fibers. The following conclusions are drawn:

Reinforcing a collapsible soil with polyethylene fibers reduced considerably the collapse potential.

To preserve the environment from pollution due to used water plastic bottles thrown in the nature, the polyethylene fibers are generally used rather than sisal fibers because this latter does not harm the environment.

\section{References}

1. Ayadat T., Belouahri B., Ait Ammar R.., 1998. Migration of fine size particles as collapse mechanism of soils. French geotechnical journal $\mathrm{N}^{\circ} 83, \mathrm{P} 73-81$.

2. Botero E. , Ossa .A, Sherwell G., Ovando-Shelley E., 2015. Stress- strain behaviour of a silty soil reinforced with polyethylene terephthalate (PET), Geotextiles and Geomembranes 43, P 363-369.

3. Chauhan M.S., Mittal S., Mohanty B., 2008. Performance evaluation of silty sands subgrade reinforced with fly ash and fibre. Geotextiles and Geomembranes 26. P 429-435.

4. Chegenizadeh A., and Nikraz H., 2012. Investigation on silty sand paper reinforcement. International Journal of Emerging Technology and Advanced Engineering Volume 2

5. Consoli N.C, Prietto P.D.M., Ulbrich L.A,1998. Influence of fiber and cements addition on behaviour of sandy soil, Journal of Geotechnical and geoenvironmental engineering 124 P 12111214.

6. Hamidi A., Hooresfand M., 2013. Effect of fiber reinforcement on triaxial shear behaviour of cement treated Sand. Geotextiles and Geomembranes 36, p $1-9$.

7. Nouaouria M.S., Harireche O., Rouaiguia A., 2002. Comportement de l'affaissement du loess, Sols et fondations, Anales du batiment et des travaux publics. P 37-41. 